\title{
A container dispatching system for river ports based on distributed business intelligence
}

\author{
Jingyuan Zeng ${ }^{1}$, Zhenji Zhang ${ }^{1}$, Xiaolan Guan ${ }^{2}$, Ruize Gao ${ }^{1}$ \\ ${ }^{1}$ Beijing Jiaotong University ${ }^{2}$ Beijing Institute of Graphic Communication (China) \\ zenginngyuan@.transsd.com.cn, zhjizhang@bitu.edu.cn,08113101@bjitu.edu.cn,12113146@bjtu.edu.cn
}

Received: September 2013

Accepted: November 2013

\section{Abstract:}

Purpose With the expansion of business scope of river ports, it demands higher loading and unloading efficiency. Automation, informatization and intellectualization become the only way to development of river ports. Because the key process in river port is container dispatching, the purpose of this paper is to design a container dispatching system, which can improve port performance.

Design/methoddogy/approadr. At first, this paper establishes an informatization framework for river ports to discuss and clarify the importance of the container dispatching system in informatization of river ports. And then, the system structure is designed based on distributed business intelligence. It contains four levels, data source layer, data warehouse layer, data service layer and application layer. The main modules are discussed in detail. At last, a KPI model is established to appraise the performance of this system.

Findings and Originality/value' This paper develops an original container dispatching system based on distributed business intelligence. Through performance comparison and analysis before and after the system implementation in Whampoa, the system is proved to have a lot of real benefits: with the system, the resource utilization rate is improved and profitless operation and the cost are reduced; the system reduces the labor intensity and labor cost and optimizes the configuration of personnel; the system helps on dynamic decision-making; it provides a way for 
real-time data interchange with government regulators and customers so that extended, personalized and interactive service can be realized.

Keywords: container dispatching system, port planning, storage optimization, business intelligence

\section{Introduction}

Usually a river port is close to the origin or the end of logistics chains. It demands timeliness and accuracy of information and services. But compared with seaports, river ports do not have the advantage on batch processing. Consequently, informatization of river ports became something valued. On one hand, it has an important practical significance on raising the terminal operation management ability. On the other hand, it helps increase the efficiency of the whole logistics chain.

Port scheduling is the most important process of port operating, especially for recent years. A lot of studies are focused on port operation optimizing algorithm and programming models. For example, Kim and Park (2004) proposed a mixed-integer programming model to obtain the optimal solution of the quay crane scheduling problem. Lee and Cho (2007) established a dynamic planning system on the basis of real-time yard tractors tracking. Jones, Farkas, Bernstein, Davis, Turk, Turnquist et al. (2011) developed a modeling tool for analysis on imports/exports containerized freight flows in U.S. and the potential changes in those flows under a variety of conditions.

And also, there are plenty of researches focused on information system (IS) for ports or other transport hubs. Keceli (2010) provided a guideline for successful development of a port community system in Turkey. Yang and Lin (2010) analyzed the construction procedure, the core function and the operation of informatization platform for ports. Li and Zhang (2010) discussed the advantages of IS for ports and introduced the data center and some main application systems of E-port in China. Yin, Khoo and Chen (2011) proposed a distributed agent system for dynamic port planning and scheduling, which comprises a port planning manager (PPM), a berth control agent (BCA), a shuttle allocation agent (SAA) and a yard storage agent (YSA). Ao, Wu and Yang (2012) designed a logistics management automation system for waterway integrated ports. Wang, Zhu and Xie (2012) developed a railway container hub scheduling system using multi-agent system theories. Liu, Wang and Yip (2013) presented the Pearl River Delta port system development to date and identify the underlying forces driving the port system evolution.

These studies discussed informatization of river ports from different aspects. However, research on container dispatching system is little. Firstly, this paper establishes an overall informatization framework for river ports. Because the key process in river port is container 
dispatching, this paper designs a container dispatching system based on distributed business intelligence. The main modules are discussed in detail. At last, through performance comparison and analysis before and after the system implementation in Whampoa, the system is proved to have a lot of real benefits.

\section{An informatization framework for river ports}

Considering the essential factors for informatization of river ports and their relationships, this section will give a general framework of it. In this paper, the framework is composed by the following several parts.

- The network infrastructure. The network is an important infrastructure for informatization of river ports. It consists of computer networks and basic communication facilities.

- Data resources platform. The data resources platform provides unified management of information resources through the method of information resource planning. In process of data collecting, transmission, analyzing and planning, it develops a unified standard for information processing and facilitates information sharing and information system integration. Data resources platform removes data barriers and businesses barriers and thus promotes horizontal integration and longitudinal penetration of the industry.

- Public information service platform. The public information service platform provides real-time information and spatial data services for each river port and its operation systems. The core technology is GPRS and GIS. It implements collection, storage and maintenance of channel geographic information and dynamic information of ships.

- Business application platform. As the application system in each business area of inland port industry, business application platform is the key point of river ports informatization. In consideration of the industry characteristics and information requirements, in the process of river port informatization planning, the application system cannot be divided entirely based on business process. Instead, it should be according to industry roles.

- Web portals. Web portals are the bridges between enterprises, administrators and the outside world. There are two kinds of them, enterprise portals and government portals. The former provides communication channel between the port and other ports, owner of cargo, shipping companies, the public and administrators. The latter displays all kinds of application systems and information resources of the ports. It is the common entrance for internal and external users. 
- Informatization environment. The environment of informatization promotes the coordination and development of it. To guide and guarantee the implement and operation of related systems, informatizaion development policy and running and safety guarantee mechanism should be built.

From the above, the informatization framework of river ports is as below. (Figure 1.)

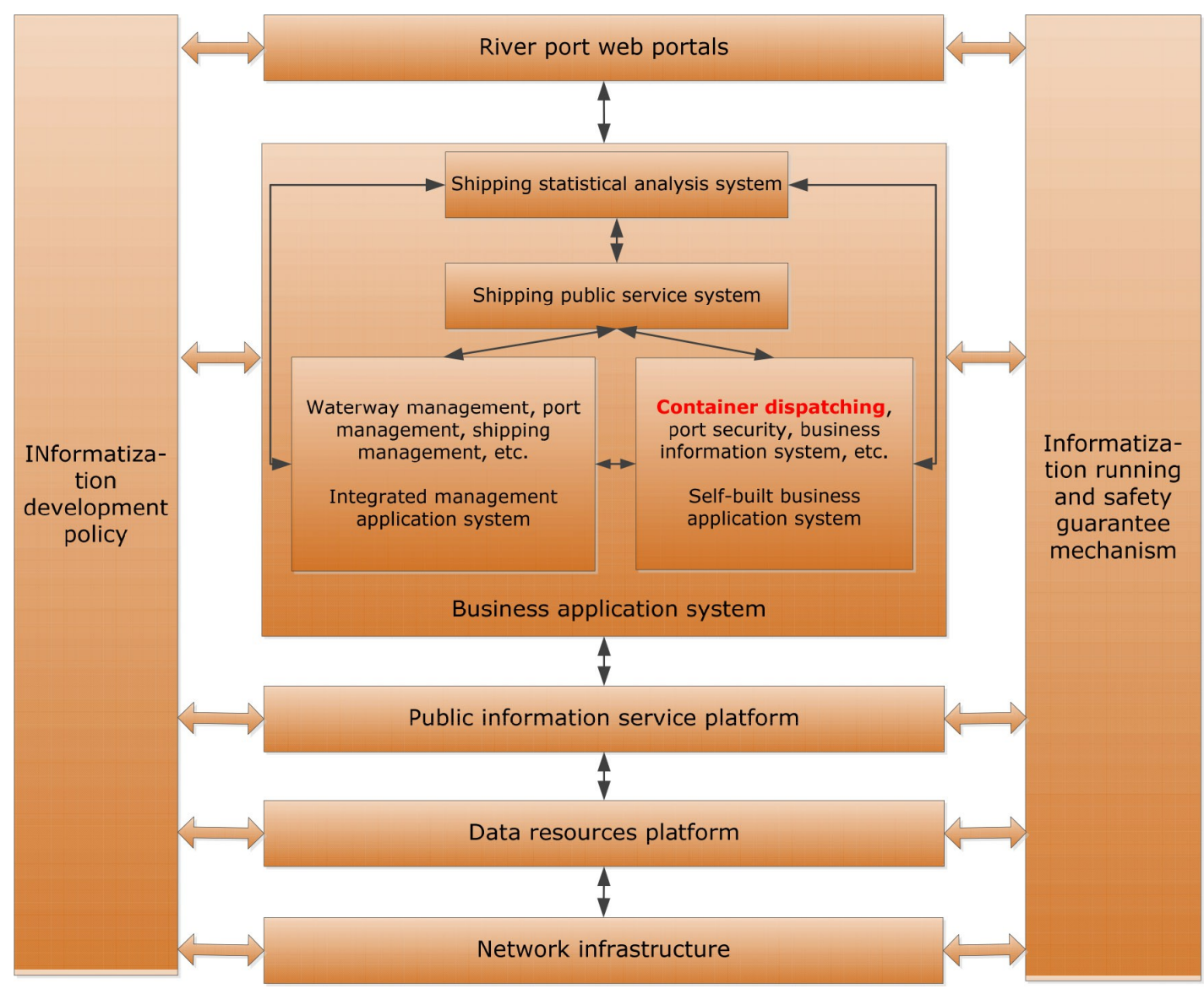

Figure 1. Informatization framework for river ports

\section{Requirements analysis on container dispatching system}

The content of river port informatization is comprehensive and complicated. The key process in river port is container dispatching. Accordingly, the core of the business application system becomes container dispatching system. A practical container dispatching system helps to control and increase the efficiency of the operation process in the river port and to reduce the cost. It brings economic benefits to the enterprises.

- Improve the utilization efficiency of storage yard, berth and equipment. Realize automated management and operation. Increase the efficiency of container handling.

- Assist and accelerate data collecting, processing and sharing.

- Help generate and give operation scheduling command instruction. Improve the efficiency and quality of services. 
Container dispatching system tracks and handles documents, ships, containers, storage yard and equipment in real time by software and hardware facilities including computer networks, wireless network, vehicle or hand-held terminals, bar coding and RFID technology. Its major functions should include documents processing, yard planning, operation scheduling, query and statistics.

\section{Container dispatching system}

The main purpose of container dispatching system is to arrange the time and location for arriving ships and to schedule the equipment and labor force for container transport. A container dispatching system based on distributed business intelligence can be divided into four levels, data source layer, data warehouse layer, data service layer and application layer (Figure 2.).

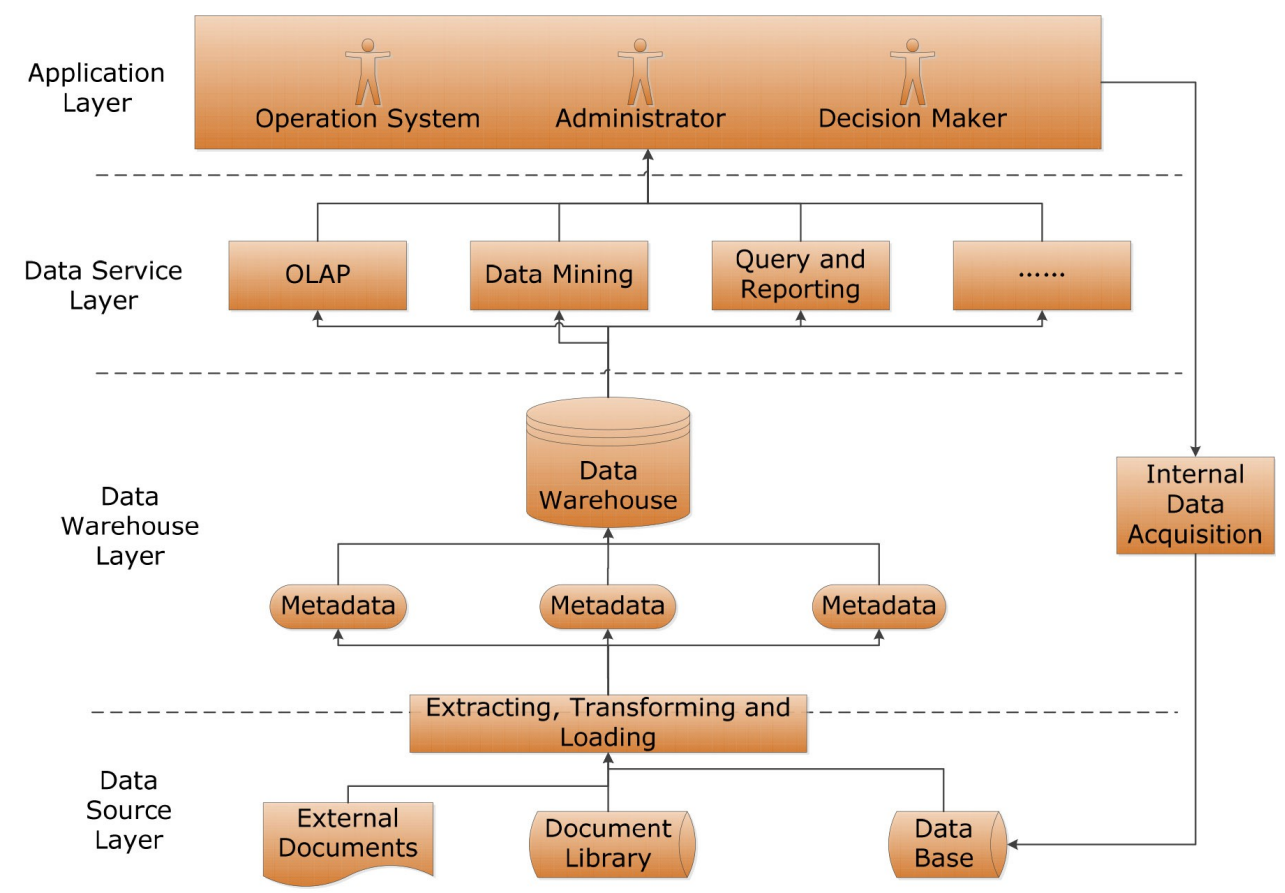

Figure 2. Four levels of container dispatching system

There are three major components of operation system, business processing system, wireless internet platform and gate integrated control system (Figure 3.). Business processing system is the kernel of container dispatching system.

The system can be classified into central system and distributed system. Both can realize information sharing between subsystems. However, their technology strategies differ a lot. The advantages of adapting distributed intelligent agent are, 1) achieve individuation and unification. The main business processes of different ports are basically the same but not in detail. Their document formats differ. It has brought difficulty to development of central systems. However, a distributed structure will reduce this difficulty and realize the development of personalized systems; 2) convenient for giving full play to initiative of each port's IT professionals. Usually every port has information management department, which is 
responsible for construction and maintenance of its subsystem. The distributed structure model for the business processing system is in Figure 4.

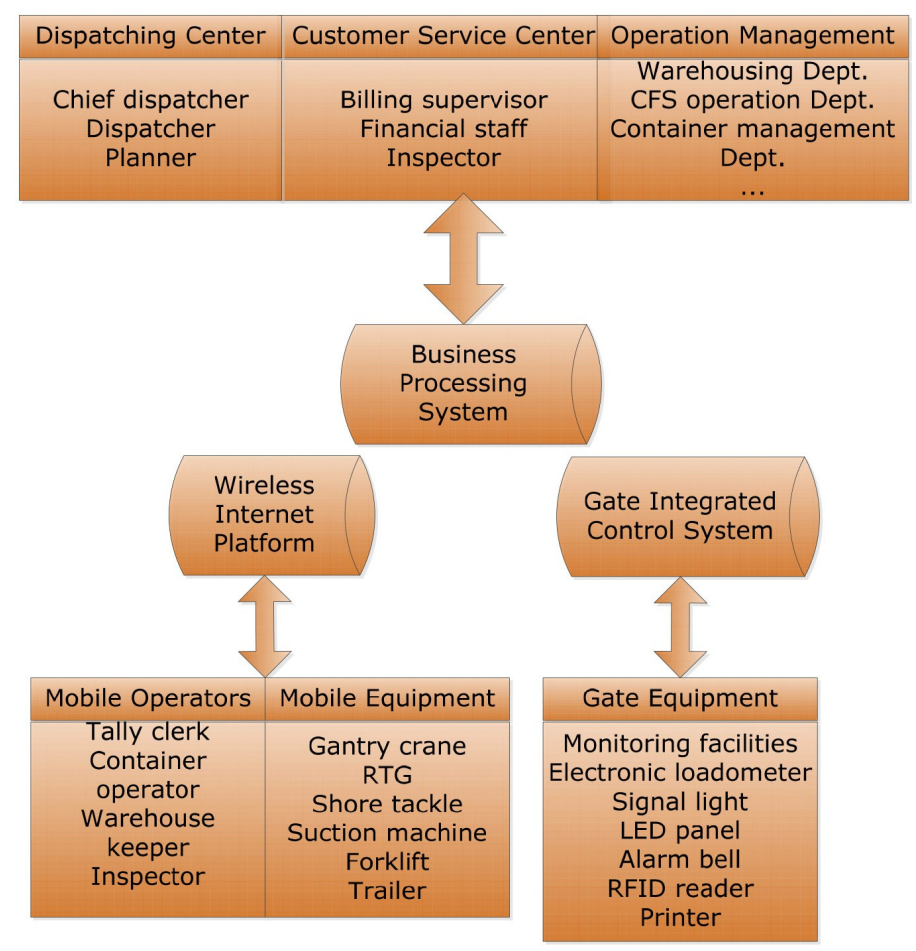

Figure 3. Operation system

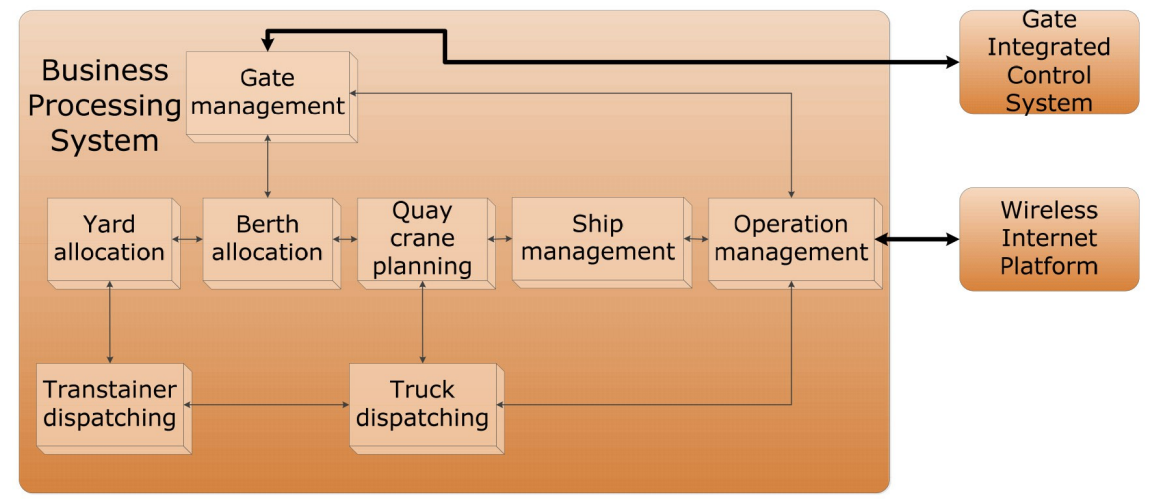

Figure 4. Business processing system

\section{(1) Data acquisition module}

There are different data sources, including different data base and different data types of subsystems. Data acquisition module comprises real time data acquisition module, timed data acquisition module and external data acquisition module. One major function of data acquisition module is internal system data acquisition, which is mainly daily data from business processing system. This module puts large amounts of historical data into data base and ensures consistency, integrity and veracity. 


\section{(2) Berth allocation module}

Berth allocation module assigns berth and scheming lay time for arriving ships. It coordinates the conflict of berth resource between ships and optimizes the allocation of berthing and operation service. Berth allocation module collects all information about ships arriving within a certain time threshold around the clock, and schedule berthing and handling service and time of arrival on the basis of ship type, volume and other information about in-operation and standby ships. The most usual strategies are first coming first serving (FIFS), high earnings first (HEF) and shortest job first (SJB). Its knowledge base stores attribute information about ships at berth and expected to arrive, containers, berth, etc. Inference engine can give the remaining berthing time, operation priority, estimated waiting time, etc.

\section{(3) Quay crane planning module}

Quay crane planning module allocates quay crane on the basis of ship type and loaded and unloaded volume. Usually this kind of assignment forms in the process of the arrival. The randomness and discreteness of arrival time, ship type and volume and container size have brought difficulty to quay crane planning. Using the inference engine and combining with operation capacity of the crane and real-time data, this module gives a reasonable and optimal scheduling decision to minimize layover time and raise handling efficient.

\section{(4) Ship management module}

There are four major functions of ship management module. 1) Make loading and unloading ship plans. This module uses optimization algorithm to make the sequence of ship for loading and unloading based on stowage plans and berth and quay crane plans. 2) Make loading and unloading operation plans. Based on cargo plan, yard plan and loading list, give ship-yard or yard-ship corresponding relation for operation of each container and list the sequence of loading and unloading operation. 3) Adjust the loading plans. Loading and unloading ship plans are made on the basis of average efficient and the crane and trailers are acquiescently available. However, there is conflict between concurrent operations because of limited equipment resources. And there might be special situations when the actual operation efficiency is higher or lower than the average. Therefore, the original plans might need to be adjusted according to actual resources usage. 4) Start, suspend or terminate and monitor and record the performance of loading plans. If a loading plan is started, this module will send operational instructions to operation management module in accordance with defined sequence. After execution, the operation management module will send back a performance report, including the time and mechanical condition. And then ship management module detects the different between performance and the plan and decides whether to adjust the plan or send further instruction as planned. 


\section{(5) Yard allocation module}

There are three kinds of disposition of containers, handled from berthing ships to the yard and then taken away from yard by customers, stored in the yard and then carried away by ships, handled from berthing ships to the port and then carried away by other ships. Disposition of containers, arrival time, container type and quantity and loading sequence affects the question of yard allocation. Usually the storage yard is divided into several separate sections which are separately managed. Each section has its storage category. The major function of this module is to assign storage area for containers and to coordinate and resolve conflict between different storage sections. Also, it demands transtainer dispatching module scheming transport operation.

\section{(6) Transtainer dispatching module}

The major function of transtainer dispatching module is to assign equipment to different storage sections, including dispatching the crane for yard operation, and to distribute specific storage location for containers. This module gets information about operation process and truck condition form communication control system. Using inference engine it estimates how busy it is in each storage section and judges conditions of crane demand for each section.

\section{(7) Truck dispatching module}

Truck dispatching module dispatch trucks inside the yard. As similar with transtainer dispatching module, this module aims at increasing the equipment efficiency. Based on the request from quay crane planning module and transtainer dispatching module, it dispatches trucks to serve horizontal transport. Truck dispatching module resolves problems about transport such as loading sequence and routing and avoids deadhead and queue whenever possible.

\section{(8) Gate management module}

Information collection from the gate has a direct influence on the stacking quality, the stowage and operation efficiency. Moreover, it is the final hurdle for the delivery of import containers. Therefore, the gate plays an important role in container management, including container handling, interchange and storage. There are three major functions of gate management module. 1) Monitor the trucks entering or leaving the storage yard. All containers transported into and out of the storage yard by trucking have to get through the gate and have an inspection. Especially for containers which might contain special items such as dangerous goods and fragile products, it has to record details including the consignor and degree of damage. 2) Containers congregation. This module receives and verifies application for congregation from customers. And then it numbers and classifies those containers and sends information and orders to yard allocation module and operation management module. 3) 
Containers pick-up. It receives and verifies application for containers delivery. And then it appoints corresponding container numbers and submits to operation management module.

\section{(9) Operation management module}

There are two major functions of operation management module. 1) After receiving operational requirements from other modules, operation management module generates operation instruction and code according to operation type and time and then sends back operation report. 2) If an operational instruction needs to execute among several terminals, this module will send the instruction to them and receive performance report by the wireless internet platform.

\section{Performance Evaluation}

\subsection{KPI model}

To accurately measure the performance of river ports, this paper establishes a KPI model (Figure 5.).

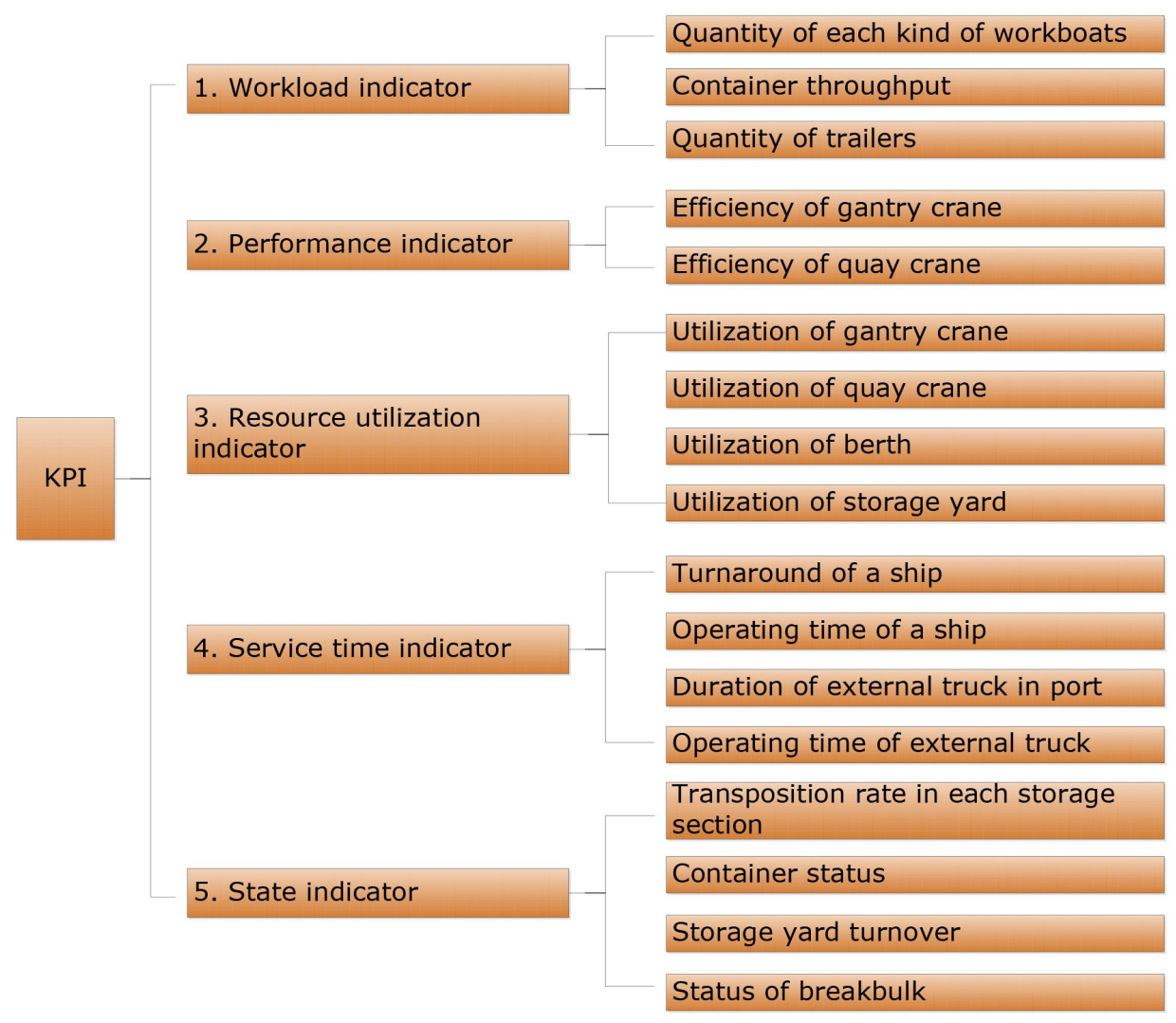

Figure 5. KPI model for performance of river ports

This KPI model provides uniform quantitative criteria for performance analysis between different ports. It helps to adapt necessary measures in time to improve the system efficiency. Also, KPI model reflects influence of different optimization plans and assists system design and solution selection. 
Efficiency of gantry crane is the average quantity of containers handled by a gantry crane during one unit of working time, including the yard throughput and transposition quantity. Efficiency of quay crane is the average quantity of containers handled by a quay crane during one unit of working time.

Resource utilization rate $(R U)$ is the average utilizing state of the resource. $R(t)$ is a Boolean variable,

$$
R U=\frac{\int_{0}^{T} R(t) d t}{T}
$$

If $R(t)=1$, the resource is in the busy state. Otherwise, it is in the idle state.

\subsection{Performance evaluation}

The container dispatching system makes the river port break through the bottleneck of container handling capacity. Taking Whampoa as an example, after the implementation of this system its container capacity is 120,000 TEU while it was 60,000 TEU before. The actual benefits of system implementation are as below.

- The system helps to improve the resource utilization rate, reduce profitless operation and the cost. Take Whampoa as an example, its transposition rate in storage yard is reduced to $42 \%$ from $71 \%$ in 5 month after the implementation of this system (Figure 6.). According to the financial analysis data, this reduces the cost by $1,656,000$ RMB/year. Through statistics and analysis of operational data, visual management level and operating efficiency can be improved.

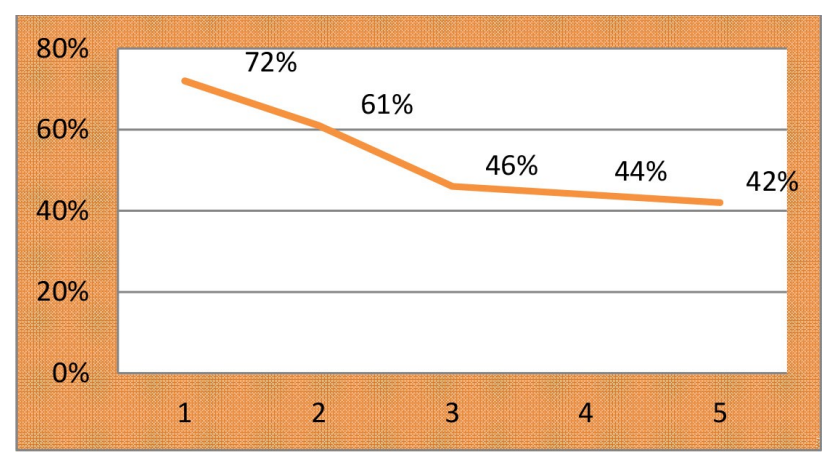

Figure 6. Transposition rate after system implementation

- The use of wireless vehicular terminals and hand-held terminal helps to reduce the labor intensity and labor cost. At the same time, it optimizes the configuration of personnel. Take Whampoa as an example, the implementation of this system reduces its labor cost by 420,000 RMB/year. 
- The system helps the port on dynamic decision-making. Real-time data collection, strengthened control of operating process and optimized operational plans make the port get rid of passive recording.

- Provision of real-time data for customers like shipping companies is the basis for extended, personalized and interactive service. The system allows those customers to acquire real-time data anytime and anywhere. At the same time, the system provides a way for real-time data interchange with government regulators such as the customs section.

\section{Conclusions}

With the expansion of business scope of river ports, it asks for higher loading and unloading efficiency. In order to adapt to the scale of container terminal operations, automation, informatization and intellectualization become the only way for development of river ports.

The key process in river port is container dispatching. At first an informatization framework for river ports is established. Container dispatching system is the core of the business application system. This paper designs a container dispatching system based on distributed business intelligence. It can be divided into four levels, data source layer, data warehouse layer, data service layer and application layer. The main modules are discussed in detail, including data acquisition module, berth allocation module, quay crane planning module, ship management module, yard allocation module, transtainer dispatching module, truck dispatching module, gate management module and operation management module. At last, a KPI model is established. And through performance comparison and analysis before and after the system implementation in Whampoa, the system is proved to have a lot of real benefits.

\section{References}

Ao, C.H., Wu, Q., \& Yang, X. (2012). Design on logistics management automation system for waterway integrated port. 2012 10th World Congress on Intelligent Control and Automation (WCICA 2012), Beijing (CHINA), 6-8 July, 3954-3957.

Jones, D.A., Farkas, J.L., Bernstein, O., Davis, C.E., Turk, A., Turnquist, M.A., et al. (2011). US import/export container flow modeling and disruption analysis. Research in Transportation Economics, 32(1), 3-14. http://dx.doi.org/10.1016/j.retrec.2011.06.003

Keceli, Y. (2011). A proposed innovation strategy for Turkish port administration policy via information technology. Maritime Policy \& Management, 38(2), 151-167. http://dx.doi.org/10.1080/03088839.2011.556676 
Kim, K.H., \& Park, Y.M. (2004). A crane scheduling method for port container terminals. European Journal of operational research, 156(3), 752-768. http://dx.doi.org/10.1016/S03772217(03)00133-4

Lee, S.Y., \& Cho, G.S. (2007). A simulation study for the operations analysis of dynamic planning in container terminals considering RTLS. Innovative Computing, Information and Control, 2007. ICICIC'07. Second International Conference on, Kumamoto (JAPAN), 5-7 Sept., 116. IEEE.

Li, Y., \& Zhang, X. (2010). Study on development and system application of china E-port. Information Management, Innovation Management and Industrial Engineering (ICIII), 2010 International Conference on, Kunming (CHINA), 26-28 Nov., 4, 430-433. IEEE. http://dx.doi.org/10.1109/ICIII.2010.584

Liu, L., Wang, K.Y., \& Yip, T. L. (2013). Development of a container port system in Pearl River Delta: path to multi-gateway ports. Journal of Transport Geography, 28, 30-38. http://dx.doi.org/10.1016/j.jtrangeo.2012.10.002

Wang, L., Zhu, X.N., \& Xie, Z.Y. (2012). Modeling and analyzing of railway container hub scheduling system based on multi-agent system. Journal of System and Management Sciences, 2(1), 31-39. http://www.aasmr.org/jsms/Vol2/No1/JSMS Vol2 No1 3.pdf

Yang, H., \& Lin, L. (2010). The construction and operation of the informatization platform of Shanghai Port. E-Business and E-Government (ICEE), 2010 International Conference on, Guangzhou (CHINA), 7-9 May, 395-399. IEEE. http://dx.doi.org/10.1109/ICEE.2010.108

Yin, X.F., Khoo, L.P., \& Chen, C.H. (2011). A distributed agent system for port planning and scheduling. Advanced Engineering Informatics, 25(3), 403-412. http://dx.doi.org/10.1016/j.aei.2010.10.004

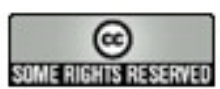

Article's contents are provided on a Attribution-Non Commercial 3.0 Creative commons license. Readers are allowed to copy, distribute and communicate article's contents, provided the author's and Journal of Industrial Engineering and Management's names are included. It must not be used for commercial purposes. To see the complete license contents, please visit http://creativecommons.org/licenses/by-nc/3.0/. 